\title{
O WhatsApp como ferramenta no ensino- aprendizagem de língua inglesa
}

\author{
El WhatsApp como herramienta en la enseñanza- \\ aprendizaje del idioma inglés
}

\section{WhatsApp as a tool in English teaching-learning}

\author{
Fábio Henrique Rosa Senefonte* \\ Marjorie Ninoska Gómez Talavera**
}

\begin{abstract}
RESUMO: É inegável a influência tecnológica nas diferentes esferas sociais do mundo contemporâneo. Assim, dentro do contexto educacional, as ferramentas tecnológicas prometem potencializar as práticas pedagógicas (COSTA; LOPES, 2015; PRENSKY, 2010 entre outros). Nesse sentido, o aplicativo WhatsApp pode ser um poderoso instrumento no ensino-aprendizagem de línguas (ARIMURA; TAKAKI, 2014; BELÉM, 2014). Levando tais premissas em consideração, este artigo apresenta uma proposta didática, com vistas ao desenvolvimento linguístico em língua inglesa, tanto nas habilidades orais quanto escritas. Esperamos que tal proposta possa contribuir para o enriquecimento teórico-metodológico na literatura, visto que há uma escassez de estudos empíricos na temática. Além disso, esta pesquisa enfatiza a importância do feedback, que por sua vez tem sido negligenciado nos estudos conduzidos na área.
\end{abstract}

PALAVRAS-CHAVE: Ensino-aprendizagem de Inglês. Tecnologia Educacional. WhatsApp.

RESUMEN:Es innegable la influencia tecnológica en las diferentes esferas sociales del mundo contemporáneo. Por lo tanto, dentro del contexto educativo, las herramientas tecnológicas prometen potenciar las prácticas pedagógicas (COSTA, LOPES, 2015, PRENSKY, 2010 entre otros). En este sentido, la aplicación WhatsApp puede ser un poderoso instrumento en la enseñanza-aprendizaje de idiomas (ARIMURA, TAKAKI, 2014, BELÉM, 2014). En este artículo se presenta una propuesta didáctica, con vistas al desarrollo lingüístico en lengua inglesa, tanto en las habilidades orales como escritas. Esperamos que tal propuesta pueda contribuir al enriquecimiento teóricometodológico dentro de la literatura, en vista que hay una escasez de estudios empíricos dentro de la temática. Adicionalmente, esta investigación enfatiza la importancia del feedback, que a su vez ha sido descuidado en los estudios conducidos en el área.

\footnotetext{
* Doutorando em Estudos da Linguagem junto ao PPGEL-UEL - Programa de Pós-Graduação em Estudos da Linguagem da Universidade Estadual de Londrina. Professor Assistente na Universidade Estadual do Norte do Paraná. fabiosenefonte@uenp.edu.br
}

**Doutoranda em Estudos da Linguagem junto ao PPGEL-UEL - Programa de Pós-Graduação em Estudos da Linguagem da Universidade Estadual de Londrina. Professora do Departamento de Línguas da Universidade Nacional da Nicarágua. marjoriegt@gmail.com 
PALABRAS CLAVE: Enseñanza-aprendizaje del inglés. Tecnología Educativa. WhatsApp.

ABSTRACT: The technological influence in the different social spheres of the contemporary world is undeniable. Thus, within the educational context, technological tools promise to enhance pedagogical practices (COSTA, LOPES, 2015, PRENSKY, 2010 among others). In this respect, WhatsApp can be a powerful tool in language teachinglearning (ARIMURA; TAKAKI, 2014; BELÉM, 2014). Taking these assumptions into account, this article presents a didactic proposal envisioning the linguistic development in the English language, both in the oral and written skills. We hope that this proposal can contribute to the theoretical-methodological enrichment of the literature, since there is a shortage of empirical studies in this theme. In addition, this research emphasizes the importance of feedback, which in turn has been neglected in studies conducted in the field.

KEYWORDS: English teaching-learning. Educational technology. WhatsApp.

\section{Considerações Iniciais}

Indubitavelmente, o século XXI tem sido cenário de uma invasão tecnológica sem precedentes (LEVY, 1999; PRENSKY, 2010). A tecnologia está cada vez mais invasiva na vida das pessoas e essa presença vem se intensificando de tal forma que o processo de interação social vem cada vez mais se ressignificando: as barreiras geográficas podem ser minimizadas pela possibilidade de comunicação instantânea, as pessoas se socializam em ambientes virtuais (muitas vezes sem nunca terem tido contato físico/ face a face com o interlocutor), ações sociais ganham novos arranjos (pagamentos, compras e outras transações são realizadas no mundo virtual), entre outras.

Nessa perspectiva, cabe destacar o lugar e o papel das redes sociais, em especial o WhatsApp, no processo de interação do cidadão do século XXI, sobretudo quando tais ações estão imbricadas no contexto educacional, foco deste estudo.

Como parte de tal invasão tecnológica, as redes sociais cada vez mais penetram o cotidiano do cidadão do século XXI, uma vez que elas têm cumprido inúmeros propósitos sociais, já que podemos: expressar sentimentos e opiniões, compartilhar momentos de nossas vidas pessoais, estudar, fazer transações comerciais, denunciar algo, marcar uma festa, mandar mensagens 
de naturezas diversas (pessoais, profissionais, por exemplo), entre tantas outras ações sociais.

A fim de corroborar o exposto, destacamos que o Brasil é um dos países que mais usam o aplicativo WhatsApp em todo o mundo (REVISTA EXAME, 2016; FOLHA DE S. PAULO, 2016). Salientamos que esse uso exponencial advém da expressiva democratização das redes de telefonia e internet no país. Dessa forma, entendemos que o WhatsApp pode ser pedagogicamente explorado, já que é um componente intrinsicamente ligado à vida dos estudantes e, sobretudo, às ações sociais desses indivíduos.

Nesse sentido, o ensino de Língua Inglesa na educação pública brasileira apresenta grandes desafios para professores. Num estudo conduzido pelo British Council (2015), os professores entrevistados concordaram que o inglês é uma disciplina que requer mais atividades lúdicas, coletivas e interativas para gerar engajamento dos alunos e envolvimento prático com a língua. Por isso, os recursos didáticos, especialmente os tecnológicos, são a principal demanda dos professores.

Em face às discussões levantadas, este artigo objetiva apresentar uma proposta didática, com vistas ao desenvolvimento linguístico em língua inglesa (doravante LI), contemplando tanto as habilidades orais quanto escritas, por meio do aplicativo WhatsApp. Em complemento, acreditamos que tal proposta seja aplicável a uma diversidade de contextos educacionais ${ }^{1}$, portanto não direcionamos a proposta a um único segmento. Ao longo do artigo, entretanto, é possível que direcionemos certas atividades a contextos específicos por razões de adequabilidade contextual. Por fim, acreditamos que tal proposta se justifica por 3 grandes razões, a saber:

a) A tecnologia, realidade diária e constante de alunos e professores, não pode ficar de fora do processo de ensino-aprendizagem, já que ela tem provado ser um rico recurso pedagógico (COSTA; LOPES, 2015; PRENSKY, 2010 entre outros);

b) A oralidade tem sido negligenciada nas aulas de língua estrangeira, por inúmeros fatores, dentre eles a superlotação das salas de aulas (o que seria um

\footnotetext{
${ }^{1}$ Educação básica (pública ou privada) e ensino superior, no curso de Letras, por exemplo.
} 
problema contornável por meio da presente proposta) (LIMA, SOUZA, LUQUETTI, 2014 e outros);

c) Por ser uma tecnologia relativamente nova, a literatura nessa temática ainda é carente em termos de pesquisa e produção de material didático, conforme evidenciado na revisão de literatura conduzida.

Levando o exposto em consideração, este trabalho traz duas seções teóricas, uma sobre tecnologia e ensino, no sentido amplo, e outra contemplando especificamente o aplicativo WhatsApp. Na sequência, apresentamos nossa proposta didática e, por fim, tecemos algumas considerações finais.

\section{Tecnologia e Ensino de Inglês}

Nas últimas décadas, o ensino-aprendizagem de línguas estrangeiras passou por duas grandes mudanças. A primeira diz respeito ao arranjo de sala de aula que, por sua vez, era centrado no professor, com base em uma pedagogia tradicional, em que o seu papel era de falar ou palestrar (transmitir conhecimento), ao passo que o aluno recebia as informações de forma passiva. Assim, estudos acerca do ensino-aprendizagem de inglês como língua estrangeira centraram-se na revolução das metodologias/abordagens: da tradução e gramática à abordagem comunicativa, por exemplo. Em seguida, professores e pesquisadores perceberam que os alunos também deviam assumir a responsabilidade pela própria aprendizagem. Espera-se que os alunos aprendam autonomamente dentro e fora da sala de aula. O campo de estudos acerca do ensino de línguas é, portanto, resultado de várias teorias de ensinoaprendizagem. Nesse viés, o ensino de línguas representa diferentes concepções sobre o que significa instruir-se e busca oferecer respostas às necessidades de diferentes contextos de aprendizagem (MARTINS; MOREIRA, 2012).

A segunda mudança diz respeito ao ambiente educacional. Nos últimos 40 anos, ocorreram avanços concernentes às tecnologias, o que por sua vez têm ressignificado práticas educativas, como o letramento (ex.: educação 
digital). Também, as últimas décadas têm sido cenário para novas políticas educacionais, por exemplo, o cultivo à diversidade linguística e o ensino de inglês como LE voltado à formação cidadã crítica (de natureza transformadora), numa sociedade globalizada (CHAPPELLE, 2003).

No século XXI, as novas tecnologias são amplamente utilizadas na Educação. Pela transição de Computer Assisted Language Learning (CALL) ${ }^{2}$ para Tecnologias de Informação e Comunicação (TIC), professores e pesquisadores têm se interessado na adoção de novas metodologias no contexto de ensino-aprendizagem de LI, já que elas podem proporcionar maior liberdade e conveniência para os alunos aprenderem em um ambiente flexível.

Desse modo, considerando que a tecnologia muda constantemente, assim como as ações das pessoas, é quase impossível pensar na educação atual sem pensar também nos muitos tipos diferentes de métodos usados para apoiar a educação de línguas (RAZAVI; GHANIZADEH;AKBARI, 2016, ZHANG, 2013; PRENSKY, 2010). Por essa razão, a tecnologia e ensino de línguas têm uma forte ligação (CRISTÓVÃO; ANJOS-SANTOS, 2015; LEVY; HUBBARD, 2005).

É importante notar que o termo tecnologia não só se refere a aparelhos como tabletes ou telas, mas às várias ferramentas pedagógicas que realizam a mediação entre o conhecimento e o educando (BELLONI, 2003). Em complemento, Spector (2015) diz que tais recursos envolvem a aplicação disciplinada do conhecimento com a finalidade de proporcionar ou melhorar o aprendizado, a instrução e/ou o desempenho. Portanto, a educação em línguas estrangeiras mediada pela tecnologia da informação leva em conta que a sociedade é pautada no conhecimento (de naturezas diversas) e cercada por uma economia global (altamente condicionada à tecnologia). Em complemento, os recursos tecnológicos podem contribuir para o desenvolvimento da cognição individual, no apoio ao ensino contextual e ao aprendizado cooperativo (RAZAVI;GHANIZADEH;AKBARI, 2016).

\footnotetext{
${ }^{2}$ CALL é internacionalmente a sigla consolidada em pesquisas sobre ensino e aprendizagem de línguas e tecnologia.
} 
Cabe destacar que todas as línguas evoluem ao longo do tempo, uma vez que elas são utilizadas por uma variedade de falantes, com diferentes necessidades e finalidades. Além disso, a atual fase da sociedade global conduz reflexões complexas em uma perspectiva que vincula linguagem, cultura, sociedade e poder dentro da ação educativa (AITCHISON 2001; WARSCHAUER, 2000).

Com o aumento do uso das ferramentas tecnológicas, muitos novos recursos pedagógicos, tais como dispositivos móveis e aplicativos de mídia social, surgiram dando nascimento a efeitos sociais e culturais de natureza multilíngue e multimodal. A grosso modo, entendemos que essas novas condições de conhecimento podem potencializar a migração de informações e ideologias (SPECTOR, 2015).

Uns dos desafios para os professores é essa aliança entre tecnologia e letramento. Nesse cenário emergem conceitos como: cibercultura ${ }^{3}$ e ciberespaçô, com suas sociedades virtuais, reservas de imagens, simulações interativas, proliferação de textos e de signos diversos, propõem novos desafios para esse letramento tecnológico (LEVY, 1999; BUCKINGHAM, 2010). O novo conceito de letramento usando tecnologia não envolve apenas o bom desempenho em leitura e escrita, mas um conhecimento significativo e consciente acerca de fatores, como identidade, cultura, relações de poder e outros. Como Dionisio (2005) posiciona, o letramento passa a ser, por conseguinte, um marco de ações sociais com diferentes objetivos. Ser verdadeiramente letrado hoje em dia significa ser capaz de usar os diferentes sistemas de símbolos dominantes da cultura para objetivos pessoais e sociais (HOBBS; JENSEN, 2013).

Portanto, a maioria dos professores de inglês parte do princípio de que seus alunos precisam praticar o inglês fora da sala de aula, se quiserem ampliar sua competência sociolinguística, mas a "prática" pode consistir em muitos tipos

${ }^{3}$ Cibercultura trata-se de um novo estudo interdisciplinar no campo da pesquisa, provocado pelos avanços tecnológicos e definido pela análise cultural da comunicação e informação, em especial, dentro do advento da internet (de um ciberespaço, por exemplo) (LEVY, 1999).

${ }^{4}$ Ciberespaço refere-se à complexa congregação de redes virtuais e aos fenômenos sociais, culturais e políticos que eles detêm (JUNQUEIRA, 2015). 
diferentes de uso da língua inglesa. Hoje, a importância da tecnologia da informação para o uso e a aprendizagem da linguagem deve ser vista de uma forma mais ampla. Essa visão deve ajudar os estudantes a ter uma visão melhor da sociedade e da vida através de uma aprendizagem mais abrangente.

Após essas discussões conceituais e teórico-metodológicas, a próxima seção diz respeito a uma revisão de literatura acerca do aplicativo WhatsApp no ensino-aprendizagem de LI.

\section{O WhatsApp no Ensino-Aprendizagem de Inglês}

Esta seção tem por finalidade abarcar questões relativas ao uso do aplicativo WhatsApp nas aulas de línguas estrangeiras no Brasil, mais especificamente, de Língua Inglesa. Para tanto, conduzimos uma revisão da literatura para dar o suporte teórico necessário às nossas discussões. Assim, entre os meses de outubro a novembro de 2016, utilizando o termo de busca "O WhatsApp nas aulas de língua inglesa", consultamos as principais bases de dados de pesquisas no Brasil: SciELO5, Banco de Dissertações e Teses da CAPES $^{6}$, Portal da CAPES $^{7}$ e Google (Acadêmico) ${ }^{8}$. Os critérios para a seleção de estudos foram:

a) Pesquisas cujo foco fosse no aplicativo WhatsApp;

b) Investigações que utilizassem o aplicativo como recurso de ensino e/ou aprendizagem;

c) Estudos cujos contextos fossem aulas de inglês;

d) Não houve delimitação de tempo e de segmento educacional.

Dentre todas as ferramentas citadas, resultados foram encontrados apenas no Google/Google Acadêmico. Após o afunilamento do escopo deste estudo, obtivemos 9 pesquisas que contemplaram os critérios

\footnotetext{
${ }^{5}$ Página oficial <http://search.scielo.org/?q=\&where=>.

${ }^{6}$ Página oficial <http://bancodeteses.capes.gov.br>.

7 Página oficial <http://www.periodicos.capes.gov.br>.

${ }^{8}$ As 20 primeiras páginas foram consultadas, totalizando, assim, 200 entradas.
} 
supramencionados. Dessa forma, dedicamos os próximos parágrafos à discussão de cada estudo encontrado. 0 quadro a seguir elucida os principais componentes de cada estudo.

\section{Quadro 1: Estudos acerca do WhatsApp nas Aulas de LI}

\begin{tabular}{|c|c|c|}
\hline Estudo & Foco & Contexto \\
\hline $\begin{array}{c}\text { Albuquerque e Bottentuit } \\
\text { Junior (2015) }\end{array}$ & $\begin{array}{c}\text { Comunicação extraclasse } \\
\text { (questões pedagógicas }{ }^{\text {}} \text { ) }\end{array}$ & $\begin{array}{c}\text { Escola de Idiomas Yázigi em } \\
\text { São Luís- MA }\end{array}$ \\
\hline Arimura e Takaki (2014) & $\begin{array}{c}\text { Curstsp como ambiente } \\
\text { para discussão }\end{array}$ & $\begin{array}{c}\text { Curras (Inglês)- } \\
\text { UFMS }\end{array}$ \\
\hline Belém (2014) & $\begin{array}{c}\text { Habilidades escritas: leitura e } \\
\text { escrita de mensagens no } \\
\text { WhatsApp. }\end{array}$ & $\begin{array}{c}\text { Curso de Licenciatura em } \\
\text { Inglês (UFPA) }\end{array}$ \\
\hline Bordini e El Kadri (2014) & $\begin{array}{c}\text { Habilidades orais e escritas } \\
\text { por meio do WhatsApp }\end{array}$ & $\begin{array}{c}6^{\circ} \text { ano do ensino fundamental } \\
\text { de uma escola pública, } \\
\text { Londrina (PR) }\end{array}$ \\
\hline Costa e Lopes (2015) & $\begin{array}{c}\text { Habilidades escritas: leitura e } \\
\text { escrita de mensagens no } \\
\text { WhatsApp. }\end{array}$ & $\begin{array}{c}\text { Curso de inglês (iniciante) em } \\
\text { um instituto de idiomas (RJ). }\end{array}$ \\
\hline Kaieski, Grings e Fetter \\
(2015) & $\begin{array}{c}\text { Habilidades escritas: leitura e } \\
\text { escrita de mensagens no } \\
\text { WhatsApp. }\end{array}$ & $\begin{array}{c}\text { Alunos de inglês e } \\
\text { programação de um instituto } \\
\text { de idiomas e uma escola } \\
\text { técnica (RS) }\end{array}$ \\
\hline Leite e Silva (2015) & $\begin{array}{c}\text { Habilidades escritas: leitura e } \\
\text { escrita de mensagens no } \\
\text { WhatsApp. }\end{array}$ & $\begin{array}{c}\text { Departamento de Linguagem } \\
\text { e Tecnologia (DELTEC)- } \\
\text { CEFET-MG }\end{array}$ \\
\hline
\end{tabular}

9 Questões pedagógicas dizem respeito a ações engendradas pelos docentes, tais como: esclarecimento de dúvidas, recados e outras práticas de sala de aula. 


\begin{tabular}{|c|c|c|}
\hline Martins e Claudio (2014) & $\begin{array}{c}\text { Comunicação extraclasse } \\
\text { (questões pedagógicas) }\end{array}$ & $\begin{array}{c}\text { Licenciatura em } \\
\text { Espanhol/Inglês (UFAC) }\end{array}$ \\
\hline Zardini (2015) & $\begin{array}{c}\text { Habilidades escritas: leitura e } \\
\text { escrita de mensagens no } \\
\text { WhatsApp. }\end{array}$ & $\begin{array}{c}\text { Curso (pré-intermediário) de } \\
\text { inglês no CEFET- MG }\end{array}$ \\
\hline
\end{tabular}

Fonte: Elaborado pelos autores.

No intuito de investigar o uso de tecnologias no ensino e aprendizagem de inglês em um instituto de idiomas, Albuquerque e Bottentuit Junior (2015) conduziram uma pesquisa com discentes e docentes naquele contexto. Dentre os inúmeros recursos tecnológicos empregados, o WhatsApp ganha destaque, uma vez que os participantes sinalizaram preferência para o uso do aplicativo, devido à familiaridade bem como à comodidade de uso do recurso. Em complemento, os docentes salientam que 0 aplicativo torna-se substancialmente prático no que tange a questões pedagógicas.

A fim de maximizar o letramento crítico de licenciandos em inglês, Arimura e Takaki (2014) conduziram um experimento, entendendo o WhatsApp como um ciberespaço, em que foram realizadas discussões de alguns temas polêmicos (centraram em uma novela que estava no ar, à época da pesquisa). Como as discussões não eram em língua inglesa, inferimos que os ganhos com o experimento não foram linguísticos, mas em termos de letramento crítico. Neste sentido, as autoras ilustram como os estudantes se tornaram mais engajados com questões ${ }^{10}$ da universidade, após a participação no projeto.

Com vistas a motivar alunos de uma licenciatura em inglês a praticar a língua estrangeira fora do ambiente de sala de aula, Belém (2014) propôs um trabalho com o WhatsApp. De forma síncrona/assíncrona, o professor iniciava com uma pergunta (centrada em algum eixo gramatical) e os estudantes respondiam de acordo com suas disponibilidades. $O$ autor, contudo, não elucida como e/ou se tal experimento contribuiu para um aprimoramento no processo de ensino-aprendizagem de língua inglesa, o que nos impossibilita formular alguma suposição ou inferência sobre o procedimento.

Em um $6^{\circ}$ ano de uma escola pública, Bordini e El Kadri (2014) conduziram um estudo com 25 estudantes voluntários. Por meio de alguns recursos tecnológicos, sobretudo o WhatsApp, os alunos foram instruídos a

10 Questões relativas à vida estudantil, tais como: cotas, passes, moradia e outros. 
executarem diversas atividades, tais como: mensagens, entrevistas, vídeos produzidos por eles, fotos, entre outros. Dessa forma, uma vez que todas as comunicações eram feitas em língua inglesa, os alunos puderam potencializar suas práticas linguísticas bem como as práticas de letramentos digitais. Ademais, as pesquisadoras enfatizam o interesse e a motivação por parte dos alunos em atividades que contemplam recursos tecnológicos.

Com duas turmas iniciantes em um instituto de idiomas, Costa e Lopes (2015) propuseram o uso do WhatsApp para que os discentes pudessem, majoritariamente, trocar informações concernentes às aulas, tais como: trabalhos, prazos de entregas e afins. Uma vez que a comunicação era feita na língua estrangeira, os autores argumentam que os alunos experienciavam momentos de desenvolvimento linguístico de forma colaborativa, extrapolando as barreiras espaço-temporais (escola, hora da aula, por exemplo).

Em uma turma de inglês (intermediária) e uma turma de programação de uma escola técnica, Kaieski, Grings e Fetter (2015) conduziram um projeto, utilizando o WhatsApp como ferramenta para que os alunos pudessem interagir e tirar dúvidas concernentes às aulas ou conteúdos. Os resultados apontaram que tal ferramenta mostrou ser bastante produtiva para as atividades pedagógicas dos cursos.

Leite e Silva (2015) conduziram uma pesquisa em um departamento de linguagem e tecnologia, focalizando o gênero chat do aplicativo WhatsApp. Embora os autores não tenham explicitado os reais participantes da pesquisa e nem de que forma as atividades (para o uso do aplicativo) foram propostas, os pesquisadores sinalizam que o trabalho com o recurso tecnológico pode potencializar as práticas de letramento dos alunos, ao mesmo tempo que os prepara para a atuação social em uma sociedade altamente influenciada pela tecnologia.

Por meio de um questionário destinado a licenciandos em Espanhol e Inglês, Martins e Claudio (2014) investigaram de que forma o aplicativo participa na vida dos estudantes, em especial, no processo de aprendizagem. A maioria dos participantes sinaliza o uso do WhatsApp para tais finalidades. Além 
disso, os dados revelam que grande parte dos docentes tem usado a ferramenta para potencializar suas aulas.

Na experiência de Zardini (2015), um grupo de WhatsApp foi criado e destinado a duas turmas de um curso de inglês no CEFET-MG. Inicialmente, o grupo era basicamente utilizado para recados acerca das aulas e compartilhamento de materiais extras (vídeos, links etc.). Posteriormente, 0 grupo passou a ser usado com espaço de debate a partir de temas propostos pela professora. A autora conclui que tal procedimento possibilitou inúmeras vantagens em termos de aprendizagem de língua, receptividade dos alunos, motivação dos estudantes em participar das atividades propostas, entre outros.

\section{DisCUSSÃO DOS EsTUdOS}

Como pudemos evidenciar, a literatura na área ainda carece de aprofundamento tanto em termos qualitativos quanto quantitativos. Pela revisão da literatura conduzida, notamos a escassez de pesquisas que contemplam o aplicativo WhatsApp, como ferramenta pedagógica na tríade ensino, aprendizagem e formação do professor de língua inglesa no Brasil.

Além disso, como elucidado no quadro 1 , as pesquisas conduzidas parecem explorar o aplicativo, majoritariamente, como ferramenta para potencializar a leitura e escrita em LI, fato que corrobora a premissa de que a oralidade é negligenciada nas aulas de línguas no Brasil. Das 9 pesquisas encontradas, apenas 1 contemplou a oralidade em LI no Ensino Fundamental. Dessa forma, fica evidente que os múltiplos recursos que o aplicativo apresenta não foram explorados em toda sua potencialidade. Também fica notório que há muito a se investigar nos diferentes segmentos educacionais existentes.

Com isso em mente, acreditamos que nossa proposta possa suprir algumas lacunas deixadas pelas pesquisas anteriores: explorar mais recursos que permitam o trabalho com a oralidade e, principalmente, oportunizar um 
feedback ${ }^{11}$ para os alunos quanto às produções linguísticas (orais ou escritas), já que as pesquisas escrutinadas parecem negligenciar tal prática pedagógica.

Após as devidas discussões teóricas, passemos, na próxima seção, à proposta didática defendida neste trabalho.

\section{Proposta Didática}

O WhatsApp 12 é um aplicativo compatível com smartphones, usado, majoritariamente, para mensagens instantâneas, desde que esteja conectado à internet (WHATSAPP, 2016). Para se cadastrar, é preciso ter um número de telefone celular. Assim, os contatos do WhatsApp Messenger precisam estar salvos na agenda telefônica do usuário. Segundo o site oficial do aplicativo, o WhatsApp é uma plataforma ${ }^{13}$ que possibilita chamadas de áudio, envios de arquivos/vídeos entre outras funções. Com isso em pauta, entendemos que o aplicativo se configura como um ciberespaço (LÉVY, 1999), conforme exposto na seção teórica deste escrito. Além disso, é notória a natureza multimodal das manifestações linguísticas encontradas no aplicativo, já que há um constante interjogo de linguagens sonoras, escritas, imagéticas e outras.

No que tange às vantagens de se usar o telefone (e o WhatsApp) em sala de aula, Souza (2013, p.21) elenca os seguintes argumentos em favor de uma pedagogia mediada por celulares: "conveniente, motivante, relevante, fácil, eficaz, rápido de preparar e atual".

Com isso em pauta, trazemos a seguir nossa proposta didática para uso do aplicativo WhatsApp no ensino-aprendizagem de inglês. Primeiramente,

\footnotetext{
11 Por falta de tradução adequada, optamos por manter o vocábulo em inglês. Por feedback, entendemos como um retorno (avaliativo) do professor ao aluno quanto ao desempenho deste nas atividades pedagógicas propostas.

${ }^{12}$ Para fins terminológicos, salientamos que o nome do aplicativo tem sido entendido como um trocadilho (por proximidade sonora) com a expressão inglesa "what's up?", que por sua vez significa "O que há de novo?" "O que se passa?".

13 No campo de estudos da linguagem, entendemos que o aplicativo funciona como um suporte, já que pode veicular diferentes gêneros, como por exemplo, a mensagem de WhatsApp.
} 
exploramos a oralidade, depois tecemos algumas considerações concernentes às habilidades escritas.

\section{Explorando as Habilidades Orais: LISTENING e SPEAKING}

Como visto anteriormente, a oralidade tem sido negligenciada em sala de aula devido a algumas limitações de naturezas diversas, entre elas a superlotação de salas de aula, sobretudo na Educação Básica pública. Com isso em mente, argumentamos que o professor pode superar essa dificuldade por meio do WhatsApp, já que a atividade proposta seria extraclasse, o que pode potencializar o tempo em sala de aula e solucionar o problema de salas numerosas. Portanto, a atividade a seguir pode ser direcionada a qualquer segmento educacional, principalmente, a Educação Básica na escola pública. Para tanto, é preciso:

a) Passo 1: A criação de um grupo no WhatsApp: 0 professor, como administrador do grupo pode coletar os números de telefone celular dos alunos $^{14}$ e criar um grupo para a turma ou turmas; o nome do grupo pode ser decidido conjuntamente com os estudantes. Enquanto administrador, o professor tem a vantagem de só ele poder adicionar pessoas ao grupo e, principalmente, poder mediar os tópicos durante as conversas no aplicativo. Como ponto negativo, os alunos terão o número de telefone do professor o que, por sua vez, pode gerar problemas dependendo da turma e maturidade deles. Portanto, o professor precisa considerar essas e outras variáveis antes de iniciar uma proposta com o aplicativo WhatsApp.

b) Passo 2: O professor pode selecionar tópicos ou perguntas (relacionadas às esferas sociais nas quais o estudante se engaja socialmente), como: qual a

\footnotetext{
${ }^{14}$ Estamos cientes de que essa questão está condicionada a uma série de fatores, tais como: disposição do aluno em fornecer o número de telefone, autorização da escola para o uso do celular em sala, entre outras. Além disso, tal proposta aumenta ainda mais o trabalho do professor, que precisa utilizar de seu pouco tempo livre para gerenciar o grupo do WhatsApp, corrigir as gravações/mensagens, enviar um feedback e outras funções. No entanto, não é nosso foco adentrar em tal discussão. Assim, argumentamos que as atividades propostas dependem das condições do contexto em que o professor atua.
} 
melhor idade para se casar? Por quê? Qual foi a melhor/ pior experiência de sua vida? Como está se sentido hoje? E outras ${ }^{15}$. Cabe ressaltar que quanto mais avançada for a turma, maior será a comunicação na língua-alvo e mais complexas serão as perguntas. O contrário vale para turmas iniciantes.

c) Passo 3: Solicitar que os estudantes gravem áudio ou vídeo, respondendo às perguntas em inglês e enviando ao grupo. Como prática de compreensão auditiva, o professor pode solicitar que os alunos reajam oralmente (relatando ${ }^{16}$ o que foi dito, concordando ou discordando de resposta do colega, propondo outras perguntas etc.) às respostas dos colegas. Dessa forma, eles praticam as duas habilidades orais concomitantemente e de forma integrada, conforme as tendências contemporâneas em ensino-aprendizagem de LI prescrevem (USÓJUAN; MARTÍNEZ-FLOR, 2006). Caso haja algum estudante que se sinta intimidado ou constrangido em enviar o áudio ou vídeo no grupo (para todos verem), o professor pode propor que se envie o material diretamente no WhatsApp do docente, assim o aluno pode se sentir mais confortável para realizar a atividade proposta.

d) Passo 4: Como relatamos anteriormente, o feedback tem sido expressivamente ausente nas pesquisas realizadas na temática em questão. Assim, nessa fase da atividade, o professor avalia o material fornecido e envia esse retorno aos alunos, podendo propor uma atividade de refacção ou outras complementares. Nessa fase, o aluno tem a oportunidade de praticar a compreensão auditiva e a produção oral, caso o professor complemente o feedback com outras atividades.

A atividade acima focaliza o instrumento de mensagem de áudio do aplicativo para a execução das tarefas propostas. No entanto, o docente pode explorar outros recursos do WhatsApp, como o vídeo e/ou chamadas para

\footnotetext{
${ }^{15}$ No ensino superior, questões atuais como a reforma do Ensino Médio, o sistema de cotas nas universidades, questões políticas (tercerização, previdência etc.), escândalo de frigoríficos, jogo 'Baleia Azul' e outras parecem ser bem recepcionadas pelos alunos. Tal fato foi evidenciado por meio do trabalho com o WhatsApp em disciplinas de habilidades linguísticas em LI, de um curso de Letras em uma universidade estadual, ministradas por um dos autores deste artigo. Já que nosso foco é apenas apresentar uma proposta didática, não vamos pormenorizar essas experiências.
}

16 Por meio de paráfrases, recursos do discurso indireto e outras. 
propor a mesma atividade descrita acima. Acreditamos que por meio do recurso de vídeo, as atividades podem ser enriquecidas, uma vez que outras linguagens podem ser contempladas, como a não verbal, por exemplo. Adicionalmente, corroboramos que o recurso visual (com linguagem não verbal) facilita exponencialmente a construção de sentido durante uma atividade de compreensão auditiva, já que o aluno terá mais componentes linguísticos para compreender/construir sentidos nas mensagens (RICHARDS, 2008).

Além disso, 0 trabalho com diversos gêneros orais ${ }^{17}$, tais como entrevistas, diálogos, debates pode ser igualmente equacionado. O professor tem a possibilidade de utilizar o aplicativo como um suporte para tais gêneros e propor atividades tanto orais quanto escritas que explorem o contexto de produção e circulação do gênero, disponibilizando as perguntas (em forma escrita ou gravada em áudio/vídeo) no próprio suporte. Como complemento, pode disponibilizar uma amostra do gênero e explorar suas características linguísticas e discursivas por meio de mensagens de áudio/vídeos gravados pelo próprio docente ou em conjunto com os alunos do grupo, em que cada um pode indicar uma característica do gênero, de forma que todos vão coconstruindo conhecimento acerca daquele gênero. Na parte de produção, os alunos podem produzir o gênero (entrevista, apresentação pessoal, seminário, por exemplo) e disponibilizá-lo no grupo, de forma que o professor acompanhe e forneça o feedback durante todo o processo.

Passemos agora a algumas ideias didáticas para a escrita e leitura.

\section{EXPLORANDO AS Habilidades de ESCRITAS: READING E WRITING}

Muitos de nós sabemos que com a prática vem a perfeição, especialmente quando se trata de ler e de escrever. Quanto mais escrevemos, por exemplo, melhores escritores nos tornamos. O WhatsApp pode ser uma ferramenta com a qual os alunos são incentivados a usar sua criatividade

17 Por delimitações deste artigo, não é nosso foco pormenorizar várias atividades didáticopedagógicas com o WhatsApp. Trazemos apenas algumas possibilidades, passíveis, é claro, de constantes revisitações e ressignificações. 
combinada com a expressão pessoal, para melhorar e fortalecer sua leitura e escrita. WhatsApp tem uma plataforma inerente que exige que os usuários usem mensagens curtas e breves. Tal modo de comunicação permite aos alunos praticarem brevidade, coerência e clareza. O uso do aplicativo pode ajudá-los a identificar jargões, abreviações e outras características próprias desse tipo em sua escrita. Também, pode auxiliá-los não só serem breves, mas também empáticos e atentos ao escolher suas palavras. Apresentamos a seguir algumas ideias para se explorar práticas de escrita e leitura por meio do aplicativo.

Passo 1: elaborar um plano com os alunos do roteiro de leituras a serem lidas durante $\mathrm{o}$ ano escolar e semanalmente. Assim, eles podem ajudar nas escolhas temáticas ${ }^{18}$ bem como na natureza dos textos explorados.

Passo 2: Enviar links das leituras de compreensão que foram selecionadas em conjunto para serem desenvolvidas em cada sessão por um número de estudantes previamente especificado no roteiro.

Passo 3: Colocar as perguntas de compreensão a serem respondidas, apresentadas e discutidas (por mensagens escritas ou de voz) dentro do grupo WhatsApp semanalmente.

Adicionalmente, focando no feedback por pares, que inegavelmente ajuda os estudantes a melhorarem a sua escrita. Além disso, pode ajudar a promover uma cultura de redação de responsabilidade.

Passo 1: Dividir os alunos por duplas dentro do grupo WhatsApp. Os estudantes selecionam semanalmente um colega diferente com o qual eles gostariam de trabalhar e obter feedback.

Passo 2: Os estudantes leem algumas das respostas de um colega baseadas nas perguntas de compreensão da atividade de leitura e de escrita.

Passo 3: Os estudantes identificam dois possíveis aspectos das respostas escritas de seus colegas para serem melhorados, tanto na forma como na função linguística.

$18 \mathrm{Na}$ mesma linha de pensamento com as habilidades orais, temas atuais e que sejam relevantes e significativos para os alunos. 
Assim, acreditamos que as duplas sentiriam a necessidade de escrever, comentar e melhorar, para que pudessem compartilhar seus trabalhos. Precisamos lembrar, também, que o professor estaria presente facilitando não apenas o feedback aluno-aluno, mas o feedback professor-aluno.

Desenvolver a confiança nos alunos é algo que também pode ser possibilitado pelo aplicativo. Mostrar o próprio trabalho escrito publicamente é muitas vezes tenso e envolvente e uma experiência assustadora para muitos estudantes. Embora, com prática, incentivo e feedback positivo, os alunos são capazes de ganhar confiança em si mesmos para serem capazes de escrever e compartilhar mais de seu trabalho no mundo digital. Essa confiança não traduz necessariamente uma escrita mais substanciada, no entanto, quanto mais confiança os alunos tiverem ao escrever, mais agradável será a tarefa na qual eles estão envolvidos e dispostos a fazer.Dessa forma, os estudantes poderão não só compartilhar suas escritas no grupo, mas também interagir com as produções de seus colegas.

\section{Trabalhando com o Letramento Visual}

Já que as imagens são tão integrantes na aprendizagem, pesquisas afirmam que $80 \%$ do que recebemos e nos lembramos é em forma de imagens (BEARNE; WOLSTENCROFT, 2007). Por isso, a importância do desenvolvimento da alfabetização visual é crítica. Imagens ajudam, inegavelmente, a aprendizagem num mundo visual, já que são portadoras de informação complementares ao texto falado (DIONISIO, 2005). As notícias vêm através de mídias visuais: revistas ilustradas, jornais, filmes e televisão, e sites visualmente atraentes com streaming de vídeo da internet. Das imagens às palavras, há uma progressão natural na maneira como processamos a informação: primeiro a imagem, depois as palavras. Uma maneira fácil de facilitar as discussões formais e informais e atividades que dão aos alunos oportunidades para decidirem e articularem gramática e escrita é através de infográficos ${ }^{19}$. Tais

${ }^{19}$ Gráficos de informação ou infográficos são representações visuais gráficas de informações, dados ou conhecimentos destinados a apresentar informações de forma rápida e clara. Os 
recursos podem dar a oportunidade de prender a atenção dos alunos e acoplar texto e imagem de uma forma criativa.

Infográficos (por exemplo, panfletos) são ótimos para pensar em atividades no WhatsApp usando médios visuais.

Passo 1: Os alunos podem trabalhar em pares para coletar alguns exemplos de infográficos. Nessa coleta, o professor pode direcioná-los a uma temática específica.

Passo 2: Eles podem compartilhar esses elementos visuais no grupo do WhatsApp para expressar suas opiniões sobre a eficácia e conteúdo (compreensão de texto) dos infográficos. O professor pode mediar essas conversas, propondo perguntas que contemplem o contexto de produção e recepção do gênero (Onde ele é produzido? Para que finalidade? Quem os lê? E outras), características tipológicas (Que gênero é esse, como você o reconhece? Quais suas características principais? E outras) e questões tangentes à estruturação linguística (Que categoria gramatical/verbal é predominante? Qual a função de determinada escolha linguística e outras). Também, o professor pode explorar a função das imagens e outros recursos presentes.

Passo 3: Os alunos podem desenvolver seus próprios infográficos em papel, digitalizá-los ou tirar uma foto, para compartilhá-los no grupo de WhatsApp e, assim, obter um feedback. É estimulável que tal infográfico seja produzido na língua estrangeira, com a mediação do docente. Assim, além de se familiarizarem com o gênero, os alunos podem desenvolver suas habilidades linguísticas.

O processo de interação seria contínuo, garantindo que o produto final passasse por diferentes processos de melhoria. A capacidade dos estudantes para expressar pontos de vista durante o processo irá confirmar a sua compreensão do papel dos infográficos como ferramentas de letramento. Estas atividades dariam a oportunidade de praticar não só a escrita, mas a oralidade,

alunos podem melhorar a cognição, utilizando gráficos para ampliarem a capacidade do sistema visual humano para ver padrões e tendências. 
já que as discussões poderão ser feitas dentro da sala de aula (ou dentro do próprio grupo por meio de mensagens de voz) para reforçar a aprendizagem.

\section{Trabalhando com Mensagens de Texto.}

As mensagens de texto referem-se ao envio de mensagens curtas de texto escrito de telefone celular para celular. O SMS (Short Messaging System) é outra forma de mensagens de texto que torna possível que as mensagens sejam transportadas de telefone para computador ou vice-versa.

Ao pensar sobre a forma como os alunos usam mensagens de texto para se comunicar com colegas, familiares e outros, devemos levar em consideração que se trata de um uso de registro mais informal, que por sua vez não deve ser avaliado como inferior. $\mathrm{O}$ uso da linguagem informal na tecnologia (LOL-laugh out loud, por exemplo), entendido por muitos como um desvio em relação à gramática normativa, é um aspecto perfeitamente comum e aceitável nas trocas da mensagem de texto, já que é algo característico do gênero.

As mensagens de texto, consequentemente, são uma oportunidade para os alunos identificarem a linguagem característica desse contexto. Os alunos enviam muitas mensagens de texto em sua primeira língua e, muitas vezes, estão interessados em aprender a escrever mensagens de texto em inglês também. Consequentemente, por meio dessa atividade de escrever a mensagem de texto, os alunos podem ter uma discussão e aprenderem algumas abreviaturas de textos úteis nos dois idiomas. Para tanto, propomos uma atividade com os seguintes passos:

Passo 1: O professor coloca no grupo de WhatsApp algumas perguntas sobre mensagens de texto, por exemplo: Qual a frequência de envio das mensagens? Quais características a mensagem de texto tem? Por que o uso de abreviaturas, siglas e símbolos? Quais abreviaturas eles conhecem? Dentre outras que poderiam surgir.

Passo 2: 0 professor solicita aos alunos que respondam às perguntas e compartilhem as abreviações, siglas e símbolos (emoticons) que eles já usam com seus colegas. 
Passo 3: Após cada um compartilhar as abreviações e siglas e/ou símbolos que conhece, o professor pode elucidar seus significados. Por exemplo, FTF (face to face), CUL8R (see you later).Dessa forma, todos do grupo aprendem todas as expressões.

Passo 4: Os estudantes podem mandar SMS entre eles no grupo, usando as características linguísticas que aprenderam em conjunto.

Essas atividades facilitarão discussões e atividades formais e informais que darão aos alunos a oportunidade de decidirem o estilo de escrita para um determinado contexto, o que não significa que o mesmo estilo será automaticamente usado em outro contexto. Ajudar os alunos a se tornarem mais conscientes das palavras aumentará seu desempenho linguístico, bem como seu vocabulário.

\section{Considerações Finais}

A tecnologia está rapidamente se colocando como o meio de revolução na comunicação e na cognição humana, o que afeta a forma como as pessoas interagem, acessam e compartilham informações. No passado, a invenção da impressão teve de aguardar a conclusão da Revolução Industrial. Em contraste, hoje, a tecnologia da informação moderna está se desenvolvendo simultaneamente com o processo comunicacional e a globalização, garantindo assim um impacto muito mais rápido nas práticas de comunicação, alfabetização, letramento. Assim, novos modelos de produção de conhecimento precisam ser ressignificados, junto com a distribuição de materiais, recursos multimodais, construção de ambientes interativos e uma melhor compreensão do conceito de tecnologia e letramento dentro do processo de ensino e aprendizagem (WARSCHAUER, 2000; MARTINS; MOREIRA, 2012).

Nesse viés, levando em consideração que o aplicativo WhatsApp é parte do cotidiano dos alunos na contemporaneidade, tentamos achar uma forma de trazer tal realidade a favor do processo de ensino-aprendizagem de inglês no Brasil. Por isso, asseveramos que o aplicativo é um poderoso recuso didáticopedagógico, já que ele oferece inúmeros recursos para o trabalho com as 
diferentes habilidades linguístico-discursivas (compreensão de leitura, conteúdo, gêneros e suas funções, entre outros), conforme mostramos ao longo deste artigo.

Em complemento, ferramentas pedagógicas requerem que se arranjem alternativas a partir de uma grande variedade de opções em relação à teoria e à prática para produzir ambientes de aprendizagem significativos. As novas tecnologias são realidade e os professores de línguas precisam encará-las de frente no século XXI (CHAPELLE, 2003).

A educação é interacional no sentido de que os professores e os alunos interagem dinamicamente, com os professores mediando os alunos que estão em diferentes níveis de aprendizagem. Além disso, cabe ressaltar que enquanto algumas tecnologias simplesmente substituem uma tarefa ou atividade existente por uma versão automatizada, outras exigem que os professores mudem a maneira como interagem com os estudantes, como selecionam e utilizam recursos didáticos e ocasionalmente reconceituam seus papéis e obrigações como docentes.

Por fim, entendemos que certas condições devem ser implementadas, para que as tecnologias sejam usadas como um recurso de aprendizado na aquisição do inglês, sem serem neutralizadas por práticas tradicionais que invalidam/negligenciam todas as potencialidades desses recursos tecnológicos. Ademais, a opção pela rede social WhatsApp como um recurso didáticopedagógico deve estar condicionada a uma cuidadosa análise do contexto de cada turma, já que esta contém alunos heterogêneos, tanto em relação à aprendizagem da língua inglesa, quanto a estilos de vida pessoais.

\section{Referências}

AITCHISON, Jean. Language change: Progress or decay? Cambridge: Cambridge University Press. 2001

ALBUQUERQUE, Odla Cristianne Patritota; BOTTENTUIT JUNIOR, João Batista.

Ferramentas da Web 2.0 no processo de ensino- aprendizagem da língua inglesa: um estudo na escola de Idiomas Yázigi na cidade de São Luís. $6^{\circ}$ SIMPÓSIO HIPERTEXTO E TECNOLOGIAS NA EDUCAÇÃO/ $2^{\circ}$ COLÓQUIO INTERNACIONAL COM TECNOLOGIAS. Recife: UFPE. Anais Eletrônicos, dez. 2015, p. 1-20. 
ARIMURA, Jane Pereira; TAKAKI, Nara Hiroko. Letramento no WhatsApp: Agência Horizontalizada em PIBIC em Letras. Letras Escreve, v. 4, n.1, p. 51-98, 2014.

BELÉM, Breno de Campos. Short Message Service e WhatsApp: interações textuais por meio de dispositivos móveis. UEADSL. ANAIS DO CONGRESSO NACIONAL UNIVERSIDADE, EAD E SOFTWARE LIVRE. Belo Horizonte: UFMG, Anais v. 2, n.5, 2014, p.1-4.

BEARNE, Eve; WOLSTENCROFT, Helen. Visual approaches to teaching writing: Multimodal literacy 5-11. New York: Sage. 2007

BELLONI, Maria Luiza. Educação a distância. Campinas: Editora Autores Associados, 2003.

BORDINI, Sueli Ribeiro Marques; EL KADRI, Michele Salles. A Utilização do Aparelho Celular nas Aulas de Inglês: relato de uma experiência. In: PARANÁ. Os Desafios da Escola Pública Paranaense na Perspectiva do Professor PDE. Curitiba: SEED, artigos, 2014, 32 p.

BRASIL é um dos países que mais usam WhatsApp, diz pesquisa. Revista Exame. São Paulo. 30/06/2016. Disponível em < http://exame.abril.com.br/tecnologia/brasil-e-umdos-paises-que-mais-usam-whatsapp-diz-pesquisa/>. Acesso em: 27 dez. 2016.

BRITISH COUNCIL. Teaching English: O Ensino de Inglês na Educação Pública Brasileira. 1.ed. São Paulo, 2015.

BUCKINGHAM, David. Cultura digital, educação midiática e o lugar da escolarização. Educação \& Realidade, Porto Alegre, v. 35, n.3, p.37-58, 2010

CHAPELLE Carol. English language learning and technology: Lectures on applied linguistics in the age of information and communication technology. John: Benjamins Publishing; 2003.

COSTA, Dilermando Moraes; LOPES, Jurema Rosa. A perspectiva docente quanto ao uso do WhatsApp como ferramenta adicional ao ensino de inglês: um experimento em um curso livre de idiomas. XIX CONGRESSO NACIONAL DE LINGUÍSTICA E FILOLOGIA. Línguas estrangeiras e tradução. Rio de Janeiro: cadernos do CNLF, vol. XIX, no 01 - Línguas Clássicas, Textos Clássicos, 2015, p. 43-54.

CRISTÓVÃO, Vera Lúcia Lopes.; ANJOS-SANTOS, Lucas Moreira dos. Por uma pedagogia de gêneros digitais para o ensino e educação inicial do professor de língua inglesa. In: RAMOS, Rosindra de Castro Guerra.; DAMIÃO, Silvia Matravolgyi; CASTRO, Solange Terezinha Ricardo de. (Orgs.) Experiências didáticas no ensino-aprendizagem de língua inglesa em contextos diversos. Campinas, SP: Mercado de Letras, 2015, p. 107-124.

DIONÍSIO, Angela Paiva. Gêneros multimodais e multiletramento. In: KARWOSKI, Mário Acir. et al. (Org.). Gêneros textuais. reflexões e ensino. Palmas: Kaygangue, p. 137-152, 2005. 
HOBBS, Renee; JENSEN, Amy. The past, present, and future of media literacy education. Journal of media literacy education, v. 1, n.1, 2013, p.1.

JUNQUEIRA, Eduardo. The Cyberculture Theories and Teacher Preparation at the LIFEUFC Project in Brazil. International Journal of Education and Development using Information and Communication Technology, v. 11, n.3, p.109, 2015.

KAIESKI, Naira; GRINGS, Jacques Andre; FETTER, Shirlei Alexandra. Um Estudo sobre as Possibilidades Pedagógicas de Utilização do WhatsApp. CINTED-UFRGS: Novas Tecnologias na Educação. V.13, n.2, p. 1-10, 2015

LEITE, Natalia Costa; SILVA, Marden Oliveira. WhatsApp: caracterização do gênero chat em contexto de ensino de línguas estrangeiras. Texto Live: Linguagem $e$ Tecnologia, v.8, n. 1, p. 85-97, 2015.

LÉVY, Pierre. A nova relação com o saber. In: LÉVY, Pierre. Cibercultura. Tradução: Carlos Irineu da Costa. São Paulo: Editora 34, p. 159-170, 1999.

LEVY, Mike; HUBBARD, Philip. 2005. Why call CALL "CALL"? Computer Assisted Language Learning, v. 18, n. 3, p.143-149, 2005.

LIMA, Laís Teixeira.; SOUZA, Sonia Maria de Fonseca.; LUQUETTI, Eliana Crispim França. O Ensino da Habilidade Oral da Língua Inglesa nas Escolas Públicas. Rio de Janeiro: Cadernos do CNLF, v. 8, n. 10-, p.86-103, 2014.

MARTINS, CLaudia Beatriz Monte Jorge.; MOREIRA, Herivelto. "O campo CALL (Computer Assisted Language Learning): definições, escopo e abrangência. Revista Calidoscópio, v. 10, n 3, pp. 247-255, set/dez 2012,

MARTINS, Nayara Santana; CLAUDIO, Elexsandra Maria Martins. O uso do WhatsApp na educação: as visões dos licenciandos da Universidade Federal do Acre. X SIMPÓSIO LINGUAGEM E IDENTIDADES DA/NA AMAZÔNIA SUL OCIDENTAL/ VIII COLÓQUIO INTERNACIONAL "AS AMAZÔNIAS, AS ÁFRICAS E AS ÁFRICAS NA PAN-AMAZÔNNIA". Rio Branco: UFAC. Anais. 2014, p. 1-20.

PRENSKY, Marc. O papel da tecnologia no ensino e na sala de aula. Conjectura, Caxias do Sul, v. 15, n. 2,201-204, 2010. Disponível em:

<http://www.ucs.br/etc/revistas/index.php/conjectura/article/viewFile/335/289>. Acesso em: 06 fev.2015.

RAZAVI, Azam;GHANIZADEH, Afsaneh.;AKBARI, Omid. Teachers ' perceptions of the use of multimedia in teaching English in official and non-official language learning settings. International Journal of Research Studies in Educational Technology. v. 5, n. 1, p. 97-109, 2016.

RICHARDS, Jack. Teaching Listening and Speaking: from theory to practice.New York: Cambridge University Press, 2008.

SOUZA, Melody Pablos. Ressignificando o Papel do Celular em Sala de Aula: Possibilidades de Utilização no Ensino de Língua Inglesa. 2013 51fls. Monografia (especialização em Língua Inglesa) -Faculdade de Humanidades e Direito da Universidade Metodista de São Paulo, São Bernardo do Campo, 2013. 
SPECTOR, Jonathan Michael. Conceptualizing the emerging field of smart learning environments. Smart Learning Environment, v. 1, n.2, p. 1-10, $2014 a$.

SPECTOR, Jonathan Michael. Remarks on MOOCs and mini-MOOCs. Educational Technology Research \& Development, v. 62, n. 3, p. 385-392, 2014b

SPECTOR Jonathan Michael. Foundations of educational technology. Integrative approaches and interdisciplinary perspectives. London: Routledge; 2015.

USÓ-JUAN, Esther.; MARTÍNEZ-FLOR, Alicia. Current Trends in the Development and Teaching of the Four Language Skills. 2 ed. Berlin: Mouton de Gruyter, 2006, 498p.

WARSCHAUER, Mark. The Changing Global Economy and the Future of English Teaching. Tesol Quartely, v. 34, n. 3, p. 511-535, 2000.

WHATSAPP. Disponível em:<http://www.whatsapp.com>. Acesso em: 27 dez.2016.

WHATSAPP chega a 1 bilhão de usuários. Folha de São Paulo (online). São Paulo. 1/2/2016. Disponível em <http://www1.folha.uol.com.br/tec/2016/02/1736093whatsapp-chega-a-1-bilhao-de-usuarios.shtml>. Acesso em:27 dez.2016.

ZARDINI, Adriana Salles. O uso do WhatsApp na sala de aula de Língua Inglesa relato de experiência em um curso de idiomas. V SILID: SIMPÓSIO SOBRE O LIVRO DIDÁTICO DE LÍNGUA ESTRANGEIRA/ IV SIMAR: SIMPÓSIO SOBRE MATERIAIS E RECURSOS DIDÁTICOS. Rio de Janeiro: Anais. PUC-Rio, 28-30 de julho de 2015, p. 112.

ZHANG, Chunqin. A Study of Internet Use in EFL Teaching and Learning in Northwest. Asian Social Science, v. 9, n. 2, p. 48-52, 2013. 